\title{
Expression of Cyclic AMP-Receptor (cARP) Proteins by Fibroblasts in Culture: Effects of Mechanical Disruption.
}

\author{
John Aghajanian*, Arthur Hand*, Scott Genutis**, Walter Tatch** and Maija Mednieks** \\ *University of Connecticut Health Center, Central Electron Microscope Facility, Department of \\ Pediatric Dentistry, 263 Farmington Ave., Farmington CT, 06030. \\ **University of Illinois at Chicago, College of Dentistry, 801 S. Paulina St., Chicago, IL 60302.
}

Recent findings have led to radical changes in the treatment of wound healing [1]. Numerous factors that play a role in the specific form of tissue regeneration that constitutes wound healing of cutaneous and oral tissues have been studied [2]. Little is known, however, about the cellular effects of the trauma that by definition is part of a wound-causing injury. Regulation of secretory responses by fibroblasts is a fundamental process in normal wound healing. The expression of the secretory form of the regulatory subunit of type II protein kinase A (cARP), has been shown to be influenced by physiologic and environmental factors such as inflammation, drug treatment, or gravitational force $[3,4]$.

The basic aim was to determine if the expression of a protein, such as cARP, which in it's secretory form appears to be associated with signal processing of environmental or hormonal stimuli, would be influenced by a simulated injury in connective tissue cells. The present study was designed to determine if cARP expression is influenced by injury to fibroblasts grown in vitro.

A cell culture of fibroblasts from healthy gingival tissue was employed as the in vitro system. The cells were grown to confluence and then the monolayer was bisected twice at right angles with a sterile scalpel to simulate wounding. At different time points after the disruption, the cells were fixed and studied using histochemical and cytochemical methods employing an antibody to cARP. Nonspecific reactivity was tested by omitting the primary antibody. Cell morphology was determined using standard transmission electron microcopy (TEM). Cell surface characteristics were determined using scanning electron microscopy (SEM).

The results showed that the fibroblasts in culture grew rapidly and had normal morphology as viewed with TEM (Fig. 1). Numerous microvilli were present, and actively dividing cells were observed. Their topographic appearance as viewed by SEM was that of active, apparently motile cells with extensive projections and multiple surface features. Immunocytochemistry results showed a rapid and extensive response in the expression of cARP after monolayer disruption (Fig. 2). A large, but relatively transient, increase of label was apparent $30 \mathrm{~min}$ after injury. Immediately after disruption the nuclei were heavily labeled. Cytoplasmic label also was increased, as was extracellular label, while none was seen in the controls. The cARP labeling had returned to basic levels by two hours post-treatment. At 24 hours all visible surface disruption had disappeared and the cultures had reformed a monolayer.

These results showed that the expression of cARP in connective tissue cells is definitely altered as a consequence of mechanical injury. Typically fibroblast nuclei contain little measurable cARP. The large increase immediately after disruption indicates that hormonal responses and cell signaling are immediate cellular responses after injury. 
References

[1] Yamaguchi Y, Yoshikawa K (2001). Cutaneous wound healing: an update. J Dermatol 28:521-534

[2] Pereira M, Simpson-Haidaris PJ (2001). Fibrinogen modulates gene expression in wounded fibroblasts. Ann N Y Acad Sci 936:438-443

[3] Mednieks MI, Epstein PM, Hachisu R, Hand AR, Esquire RG (1994). Cyclic AMP-reactive proteins in human saliva. Arch Oral Biol 39:869-875.

[4] Mednieks MI, Burke JC, Sivakumar TP, Hand AR, Grindeland RE (2000). Secretory Proteins Characteristic of Environmental Changes in Cellular Signal Transduction: Expression in Oral Fluid. Proceedings, Int. Space Technology \& Applications International Forum. Biomedical Research on the International Space Station.

[5] The authors would like to thank Dr. Frank Nichols, UCHC Department of Periodontology, for providing the cell cultures, and Mr. David Serwanski for expert technical assistance. Supported by NIH grant DE 10105 and UCHC.
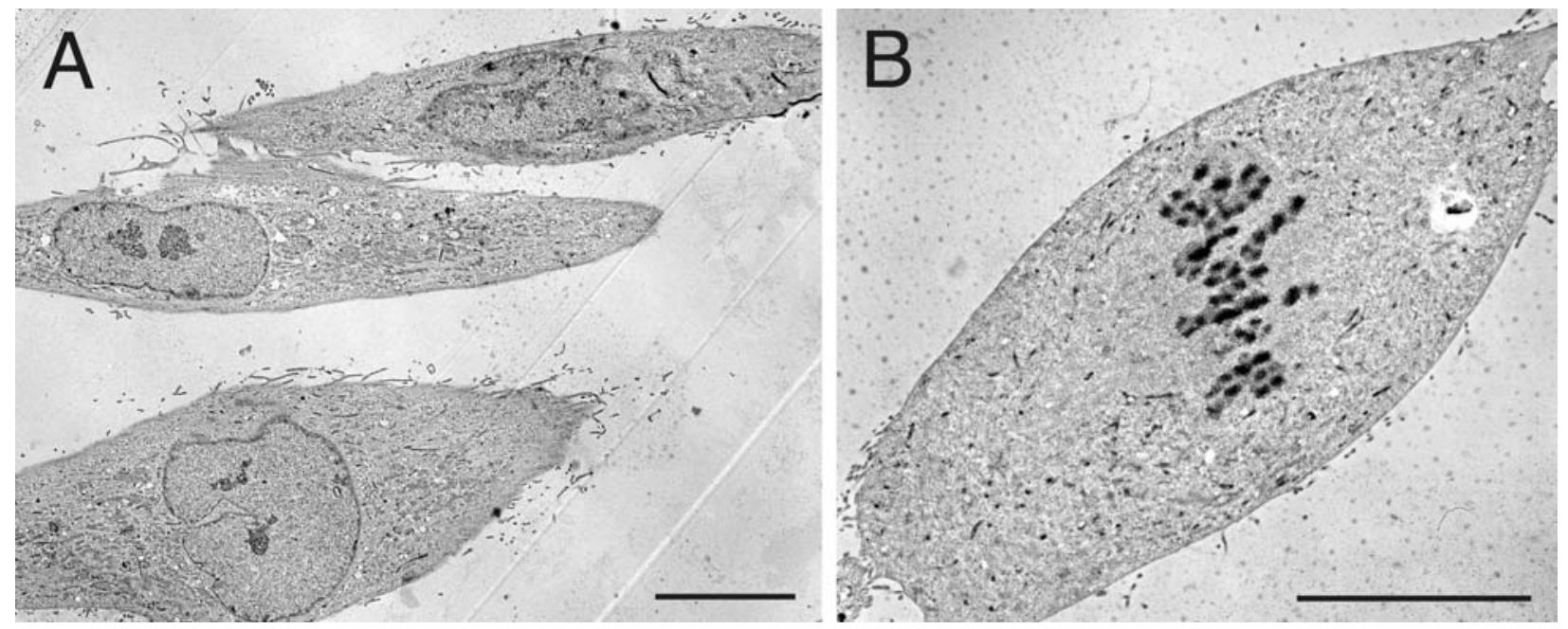

Figure 1. Electron micrographs of fibroblasts in culture: panel A, formation of a monolayer $24 \mathrm{~h}$ after wounding procedure; panel B, a mitotic cell seen after monolayer disruption. Bars $=5 \mu \mathrm{m}$.

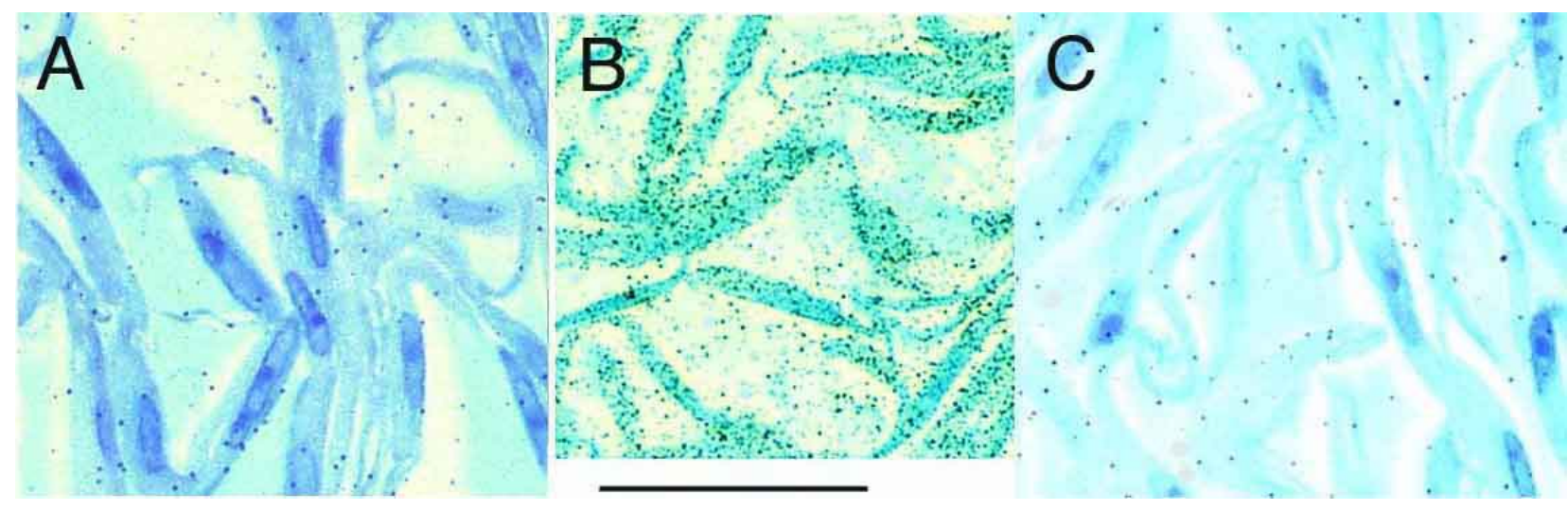

Figure 2. Light microscopic images of silver enhanced immunogold labeling of fibroblasts in cell culture: panel A, immediately after monolayer disruption, panel B 30 min and panel C $24 \mathrm{~h}$ after injury. $B a r=25 \mu \mathrm{m}$. 